\title{
Caminhos de memória: uma análise de percursos de italianidade no Rio Grande do Sul
}

\author{
Luís Fernando Beneduzi*
}

Resumo: No turbilhão da modernidade, a memória individual não é mais suficiente para reter todas as experiências passadas, criando a necessidade de instituições de preservação que as aromatizem para a contemporaneidade. Nesse sentido, discute-se as representações de italianidade, no Rio Grande do Sul, a partir dos suscitadores de memória narrados por Primo Levi, buscando entender os fragmentos do passado, presentes nos percursos turísticos, como formadores de um imaginário sobre a imigração italiana.

Abstract: In modern times, the individual memory isn't enough to retain all past experiences and the society creates preservation institutions that will smell them to the contemporary world. In this sense, its discuss the representations of the Italian identity in Rio Grande do Sul from the "memory stimulator" present in the Primo Levi's narratives; its try to understand past fragments remained in the touristic itinerary as builder of a imaginary about the Italian Immigration.

Palavras-chave: Memória. Imigração italiana. Patrimônio cultural.

Key words: Memory. Italian Immigration. Cultural Heritage.

A obra de Primo Levi tem um de seus sentidos fundantes na discussão dos instrumentos de preservação da memória. Percorrendo seus escritos, desde Se questo è un uomo - vinculado a sua experiência em Auschwitz - passando por I sommersi e $i$ salvati - até L'altrui mestiere, a marca da necessidade de recordar e de contar as gerações futuras é um elemento de destaque. A experiência comum entre os judeus na Segunda Grande Guerra - vivida também por Levi - dará o tom a essa "luta" para vencer o esquecimento, pois os acontecimentos do

\footnotetext{
* Doutor em História pela Universidade Federal do Rio Grande do Sul e Professor da Università degli Studi di Bologna. E-mail: beneduzi@lingue.unibo.it
}

Estudos Ibero-Americanos, Porto Alegre, v. 35, n. 1, p. 40-55, jan./jun. 2009 
Shoah não podem ser apagados por uma amnésia. Portanto, permanece entre aqueles que sofreram a experiência do lager o dever de recordar, porque esquecer pode significar anistiar.

A vivência como prisioneiro de um campo de concentração marcará toda a existência posterior de Primo Levi, orientando seus escritos, fomentando suas discussões e-possivelmente-norteando seu suicídio. A escolha pela literatura, vista sua formação como químico, pode ser inserida nessa necessidade de narrar não apenas as misérias do nazismo e os instrumentos de destruição do "humano", mas, também, o ofício de mnemosine. Ressalta-se, no entanto, que não se pretende tecer uma comparação entre a necessidade de recordar dos sobreviventes dos campos de concentração e dos imigrantes italianos, visto que participam de experiências extremamente diferentes. Essa pequena apresentação de Primo Levi serve para contextualizar sua preocupação com questões relativas à memória, as quais estarão presentes neste artigo.

Nesse sentido, I Racconti - particularmente os fragmentos que serão trabalhados, que se referem ao subitem Storie Naturali - apresentam instrumentos e estratégias construídas para conservação das lembranças de eventos passados. Esta narrativa de Levi permite evocar a necessidade contemporânea de institucionalizar o "ato de recordar", tendo em vista um processo contínuo de aceleração do tempo histórico e de transformação vividos pela modernidade. A fluidez dos acontecimentos, devido a uma vida frenética, produz e reproduz constantemente significados e leituras atualizadas, o que torna passado remoto as vivências do ontem, criando uma sensação de amnésia quotidiana.

Outro elemento importante de ser observado na figura de Primo Levi, como parte da "missão" de narrar as experiências passadas e construir uma linha de entendimento do acontecido, é sua realidade ímpar de cruzamento entre a memória individual e a coletiva. A memória individual é construída a partir da interação com o grupo social, pois apesar de ser o indivíduo que recorda - no sentido físico - é o grupo que constrói aquilo que é memorável. ${ }^{1}$ Entretanto, a narrativa de Levi apresenta este sentido literal - a lembrança daquele que viveu o passado - e o sentido de construção coletiva, haja vista que seus escritos são instrumentos para a leitura que o grupo faz de suas vivências e para a elaboração de uma representação social sobre as vivências (des)humanas no transcorrer do século XX.

${ }^{1}$ BURKE, Peter. Varieties of Cultural History. New York: Cornell University Press, 1997. 
O objeto de discussão do presente paper se insere nesta possibilidade de leitura de Primo Levi como um espectador/narrador privilegiado de sua época, o qual discutiu questões candentes quando do tempo da escritura e as quais permanecem ainda hoje norteando as discussões no campo das Ciências Humanas e das Letras. Dessa forma, Storie Naturali constitui-se - também - em fruto de uma preocupação com este passado que não pode morrer, com este homem que deve construir instrumentos para manter-se vivo, muitas vezes a partir da experiência fantástica da ciência. $\mathrm{O}$ autor, então, adentra uma discussão própria da modernidade, a qual se apresenta em Kant, em Baudelaire, em Benjamin, em Proust, qual seja, o tempo que avança inexoravelmente - em uma aceleração própria do ethos moderno. Com isso, os tênues fios que tramam uma história linear se rompem, permanecendo apenas os fragmentos da ação, mas estes devem ser mantidos, pois permitem uma dinâmica de leitura da passeidade.

Além da dimensão específica da memória, busca-se inter-relacionar o olhar de Levi sobre a modernidade - como construção do esquecimento, portanto, marcada pela nostalgia das experiências transcorridas - com a dinâmica contemporânea de "guardar", colecionar, entendida como marca identificadora de um pertencimento. Por um lado, a modernidade produz o esquecimento, porque apresenta uma pluralidade bem maior e efêmera de signos; por outro, instituições e associações, que são fruto do acelerado processo de transformação da sociedade atual, buscam edificar - a partir de vestígios - uma liturgia da lembrança. ${ }^{2}$

A viagem através das leituras mnemônicas das storie naturali inicia pelos mnemagoghi, ou como o próprio Levi traduz: os suscitadores de memória. Dentre os diversos contos da obra, esse se caracteriza como o mais especificamente voltado à discussão sobre a necessidade de guardar fragmentos da vida como forma de reviver o passado. Particularmente, propõe-se a construção desses vestígios, porque neles estaria contida a essência das experiências vividas.

Os mnemagoghi são objetos conectores entre a realidade presente e a experiência passada - que assim como construídos em nossos processos de reelaboração através do tempo - constituem-se nos instrumentos de ressurreição das sensações passadas, da memória. Narrando o

2 Nesse sentido, as dinâmicas de preservação da "italianidade" na serra gaúcha são parte de uma necessidade nostálgica de reviver o passado. Mesmo que desterritorializado e atemporal, os descendentes dos imigrantes criarão vínculos através de fragmentos do real acontecido, produzindo a verossimilhança e uma representação de como tudo se passou um dia. 
encontro entre um jovem médico - doutor Morandi - recém-chegado a uma pequena cidade alpina e o antigo médico da localidade - doutor Montesano - Levi discute sobre o processo evocativo dos sentidos na produção e preservação da memória. ${ }^{3}$

$\mathrm{O}$ ancião, em meio ao colóquio que se estabelece entre os dois, revela um hábito de análise desenvolvido por ele - pouco científico, admite - mas que permite o trabalho com os sentidos. Discorrendo sobre as formas como as pessoas conservam o passado - flores secas, livros, cartas como instrumentos evocativos de uma rememoração ele, como farmacêutico, produziu uma série de odores que o fazem recordar momentos da vida. Montesanto enfatiza que esses cheiros têm um efeito evocativo pessoal a cada indivíduo, retratando lugares de memória experimentados. Ao abrir um dos frascos, Montesanto questiona Morandi sobre as imagens que acorrem à sua mente e esse responde prontamente: "é cheiro de quartel" - sendo retrucado pelo médico ancião: "para mim é cheiro de sala de escola infantil, de minha sala de aula, uma mistura de ácidos graxos voláteis e acetona”.

Assim, apresenta-se o sentido mnemônico desse conjunto de odores, os quais para alguns podem ser apenas uma combinação de produtos químicos, ou até uma substância específica, mas para aquele que os têm como elementos evocativos produzem um quadro do passado, retratando eventos e qualificando momentos:

Conservo, inclusive, a fotografia dos meus trinta e sete colegas da primeira série, mas o odor deste frasco é enormemente mais eficaz em reevocar a mente as horas intermináveis de tédio debruçado sobre o silabário; as preocupações específicas das crianças (eu criança!) na espera terrível da primeira prova de ditado. [...] Quando sinto o seu cheiro, então, minhas vísceras se movem como quando eu tinha sete anos e esperava o momento de ser sabatinado. ${ }^{4}$

Muitas vezes, entretanto, como em um momento de memória involuntária, o passado pode ser ressuscitado, trazendo - inclusive vivências e relacionamentos que se gostaria de manter enterrados, pois ainda nos causam dor. Uma experiência involuntária - assim como

3 No que se refere à discussão sobre a representação do passado, destaca-se o artigo de Paul Ricoeur, o qual apresenta a memória como ponto de partida para a leitura do acontecido. RICOEUR, Paul. L'écriture de l'Histoire et la representation du passé. In: Annales. Paris: École des Hautes Études en Scienses Sociales, ano 55, n. 4, julhoagosto de 2000. Nesse sentido, a memória funcionaria como elos suscitadores do olhar histórico sobre o passado, participando da operação historiográfica.

4 LEVI, Primo. I racconti. Storie Naturali, vizio di forma, Lilit. Turim: Einaudi, 1996. p. 10 - Todos os textos em língua estrangeira foram traduzidos pelo autor. 
aquela, descrita por Proust, da madelaine banhada no chá - pode recriar acontecimentos até então enterrados a partir de um estímulo não esperado do presente: "Imagine, caro leitor, ontem eu mergulhei um bolinho numa xícara de chá, e então me lembrei que tinha morado no campo quando criança". ${ }^{5}$

Esse retorno imprevisto do passado é promovido por Morandi, o qual começava a se familiarizar com o jogo. Tomando a iniciativa, o jovem médico abre um dos frascos, que tinha odor de pele limpa, de verão, perguntando a Montesano o que aquele cheiro significava. Colocando o frasco no lugar, deu uma resposta curta: "Este não é um lugar, nem um tempo. É uma pessoa". ${ }^{6}$ Em seguida, fechou o armário, concluindo a experiência e criando um grande constrangimento no interlocutor.

Dentre os diversos compostos elaborados para recordar os momentos importantes do passado, Montesano havia mantido também a memória de alguém que tinha feito parte de sua vida. Nem todos os frascos deveriam ser abertos nesta liturgia da lembrança, pois alguns eventos do passado devem lá permanecer. Porém, o presente e as imagens que ele apresenta podem recriar - involuntariamente - sensações que pareciam mortas, às vezes relativas a um luto não feito. Nesse sentido, Lowenthal apresenta uma idéia de passado como um imenso fantasma coletivo, para além da possibilidade de ser exorcizado. Assim, ele inicia um processo de ressurreição, no qual o espectro vai se fazendo ver e ouvir: "fazendo reviver os objetos que recebem seus ecos, preparando-se para se colocar nos cérebros que estão de acordo com ele".?

A idéia de reprodução dos objetos e das pessoas, bem como a busca da construção do "igual", uma necessidade da construção mimética, é apresentada por Levi em L'ordine a Buon Mercato e Alcune applicazioni del Mimete. Nesse conto, ele apresenta uma máquina revolucionária o Mimete - ela reproduz qualquer coisa, associando as combinações químicas originais e recriando o objeto. A partir das misturas de compostos de carbono e outros elementos vitais, o pabulum daria ação a esta atividade de construir duplos - atendendo às necessidades de reprodução do mercado. Aquilo que se queria reproduzir seria colocado de um lado do aparelho e - do outro lado - seria materializado o seu "igual".

5 BENJAMIN, Walter. Obras escolhidas I. Magia e técnica, arte e política: ensaios sobre literatura e história da cultura. São Paulo: Brasiliense, 1994. p. 39.

6 LEVI, Primo. Op. cit. nota. n. 04, p. 12.

7 LOWENTHAL, David. El pasado es un país extraño. Madrid: AKAL, 1998. p. 42. 
O autor apresenta várias experiências, com objetos diversos - de diamantes a legumes - sempre buscando testar as capacidades do novo engenho. Por fim, a elaboração da questão central da humanidade: seria possível recriar um outro ser humano? Fosse uma tentação de ser criador ou uma clonagem avant la lettre, o mimete possibilitava recriar pessoas e - segundo Levi, quando fala de algumas de suas aplicações - de produzir esses novos indivíduos idênticos inclusive no caráter.

A rigor, a discussão trazida pelo autor desvela uma dinâmica própria do paradigma científico e da modernidade - a busca da reprodução contínua e da criação de duplos. A lógica do consumo - destruindo a aura dos objetos - cria a possibilidade de sua constante imitação, produzindo, dessa maneira - a cópia. O objeto perde a sua força de exclusividade, diluindo-se em diferentes versões suas, as quais permitem um fácil acesso ao seu uso, mas trazem a destruição de sua eternidade.

Entretanto, Levi aprofunda a discussão acerca dessa capacidade de construção do "igual", trazendo um novo elemento em Alcune applicazioni del Mimete. Quando Gilberto duplica sua esposa - Emma - acaba tendo de duplicar a si próprio, pois com o passar do tempo a situação começa a se tornar insuportável. A dificuldade não se apresenta por uma incapacidade de Gilberto lidar com suas "duas" mulheres, mas porque a relação entre o original e a cópia entra em crise. Efetivamente, a discussão se instaura devido a uma questão fundamental que as diferencia: o fato de uma ser a original e outra a cópia:

Em Sevilha, depois de uma jornada com um programa sobrecarregado, surgiu uma discussão, em um clima de irritação e cansaço. Surgiu entre duas mulheres, sobre o único argumento que poderia permitir uma divergência entre as suas opiniões, e efetivamente divergiam. Tinha sido oportuna ou não, lícita ou ilícita, a ação de Gilberto? Emma II tinha dito que sim, Emma I não tinha dito nada. ${ }^{8}$

Por mais semelhante que a cópia possa ser do objeto original, permanece ao menos uma diferença: o segundo constitui-se em uma reprodução do primeiro. Embora produza uma relação de verossimilhança com o indivíduo pré-existente, o que resulta dessa aproximação com o real é um processo de elaboração de uma representação do original. Emma II não será nunca a mesma Emma I, mas produzirá um efeito de "igual" para aquele que observa desde fora do processo. Nesse sentido, percebe-se uma leitura da modernidade como construtora da

${ }^{8}$ LEVI, Primo. Op. cit. nota n. 4, p. 75. 
padronização e - ao mesmo tempo - da diferença, pois ambas fazem parte da dinâmica dos processos de modernização.

Nessa apresentação de alguns contos de Primo Levi, constitui-se em reconstrução importante o relato sobre Patrizia, apresentada pelo autor em La Bella addormentata nel frigo. A narrativa é produzida em forma de diálogo entre os diversos personagens, os quais se reúnem para um evento muito especial, o qual se repete uma vez por ano, todos os anos. O casal alemão Peter e Lotte recebe quatro amigos para uma festa de aniversário especial, no qual a festejada é Patrizia. Está-se em Berlim, no dia 19 de dezembro de 2115, esperando por um evento insólito - muito embora tenha se tornado algo regular na vida desse grupo - o descongelamento de uma mulher, aquela que a pouco se denominou Patrizia.

Essa bela adormecida foi congelada em 1975, depois de uma série de testes de caráter físico, psíquico e intelectual, sendo escolhida como a melhor da raça para representar seus contemporâneos diante das gerações futuras. Dessa maneira, ela deveria ser descongelada apenas umas poucas vezes, quando aconteciam eventos de grande importância e, certamente, na data de seu aniversário. O processo de decrepitude seria, então, reduzido aos poucos períodos de saída do freezer, sendo que nestes 150 anos Patricia não havia envelhecido mais que dois ou três anos. Assim, procurava-se levar o mais adiante possível no tempo, permitindo guardar para os homens do futuro o testemunho efetivo dos acontecimentos mais importantes do passado comunitário. No final, Patrizia consegue escapar da prisão gélida e viaja para os Estados Unidos, para encontrar um outro seu coetâneo, também ele congelado para participar da mesma experiência.

O conto apresenta uma outra característica da modernidade, a necessidade de guardar experiências e sensações - em primeira pessoa - para o futuro. Nesse processo acelerado de perda, é forçoso preservar vestígios da existência para recriar as vivências passadas. $\mathrm{O}$ medo da destruição mnemônica do acontecido - do esquecimento constitui-se em parte da própria essência das narrativas de Levi, que marca esse dever de memória dos judeus sobreviventes aos campos de concentração. $\mathrm{O}$ tempo escorre em uma velocidade sempre crescente e o ser humano busca diminuir seu ritmo, se possível pará-lo, elaborando uma nova relação entre passado, presente e futuro, a partir da produção de ruínas.

Essa situação de desestruturação de relações de sociabilidade e sensibilidade vinculadas a um mundo ancestral ocasiona uma necessidade 
permanente de reevocação da tradição e de preservação de restos desse mundo que vive enquanto representação: "ma estrutura em processo de desaparecimento e que convida a um permanente e obsessivo processo de reconstrução no plano imaginário". ${ }^{9}$

As necessidades ressaltadas por Levi - produção de duplos, elaboração de suscitadores de memória, necessidade de guardar adquirem ainda maior compreensão quando pensadas em um processo de aceleração do tempo histórico, mencionado no início do paper, que produz a destruição do eterno, pois "tudo o que era estável e sólido desmancha no ar". ${ }^{10} \mathrm{O}$ fenômeno da modernidade pode ser lido a partir dessa percepção de um de seus contemporâneos - Karl Marx - que apresenta essa capacidade ao mesmo tempo produtiva e destrutiva do mundo moderno. Da mesma forma, Marshal Berman - em sua obra clássica "Tudo o que é sólido se desmancha no ar"11 - analisa esse fenômeno de produção do transitório, parte do próprio avanço do capitalismo e da destruição das sociedades tradicionais, dinâmica própria da modernidade.

Enquanto marca da modernidade, o novo instituiu-se como sinal de progresso e evolução na trajetória humana, sendo marca da destruição da tradição e do avanço das relações capitalistas. Assim, a instauração de uma racionalidade burocrática trazia consigo um processo de decadência desses vínculos ancestrais, cunhados com o estigma do arcaísmo restava o "era uma vez". Dessa maneira, o moderno cria um paradoxo entre a necessidade de produzir o novo e o medo constante de perder o passado; o avanço da urbanização e do capitalismo destrói a sociedade tradicional, mas ao mesmo tempo cria instituições para preservação e construção dessas relações que estão se esfacelando. A perda de realidade que a modernização está produzindo tende a ser combatida por itinerários de rememoração - os quais se vinculam, ainda, a projetos nacionais que se multiplicam no continente europeu e americano.

Ao mesmo tempo, esse século XIX - lugar de produção do novo e de destruição dos vestígios do velho - elegerá a nostalgia como grande tema da produção de seus romances - particularmente nas obras dos franceses Vitor Hugo e Charles Baudelaire, mas, também, em diversos

${ }^{9}$ GONÇALVES, José Reginaldo Santos. A retórica da perda: os discursos do patrimônio cultural no Brasil. Rio de Janeiro: UFRJ, 1996. p. 28.

${ }^{10}$ MARX, Karl; ENGELS, Friedrich. Manifesto do Partido Comunista (1848). Porto Alegre: L\&PM, 2001. p. 29.

11 BERMAN, Marshall. Tudo que é sólido se desmancha no ar. Aventura da Modernidade. Lisboa: Edições 70, 1982. 
românticos da Europa do Oitocentos. Segundo Antonio Prete, será a partir do romantismo que a nostalgia iniciará sua trajetória conceitual da esfera médica para aquela da literatura. ${ }^{12}$

Nesse sentido, de uma perda contínua e sem retorno, construir-se-á - na literatura do século XIX - um processo de apropriação conceitual da nostalgia - enfatizando esse indivíduo mutante que continuamente vivencia a perda de seus referenciais mnemônicos. O homem moderno vive em um turbilhão de transformações e convive constantemente com as dinâmicas da destruição e do luto:

'O viandante olha estas vastidões envoltas em luto, e em seus olhos afloram lágrimas de histeria - hysterical tears' - escreve Baudelaire em sua introdução aos poemas de Marceline DesbordesValmore. ${ }^{13}$

A dinâmica estabelecida entre memória e esquecimento será também a tônica do século XX, particularmente depois das tragédias experimentadas pelas duas Grandes Guerras. Cada vez mais, produz-se a necessidade de elaborar estratégias para resgatar essas tradições perdidas, reconstruí-las - permitindo, assim, um reencontro com esse passado partindo de releituras dos vestígios que delas permaneceram.

O Novecentos apresentará um reforço nessa busca de evasão da realidade presente, marcada pela perda. Assim, percebe-se um reforço na elaboração de percursos de viagem, na construção de uma nova experiência do espaço, através de um mergulho no eterno - naquilo que permanece - visto em contraposição com o contemporâneo, que vive o constante desaparecimento. $\mathrm{Na}$ verdade, esta dinâmica de busca de um encontro com o monumental e duradouro será a tônica dos roteiros vague à l'âme, ainda no século XIX, conduzindo a procura da segurança e da estabilidade:

O viajador adora confrontar-se com cenários grandiosos, com paisagens sublimes. Do alto das escarpas, próximo aos precipícios, ele vai se entocar nas encostas do montes, na metade do caminho entre o cume ensolarado e o vale tranqüilizador. As suas leituras o convidam a comparar-se com o bom selvagem que habita nestes lugares solitários. ${ }^{14}$

12 PRETE, Antonio. Nostalgia. Storia di un sentimento. Milano: Raffaello Cortina, 1996.

13 BENJAMIN, Walter. Obras Escolhidas III. Charles Baudelaire, um lírico no auge do capitalismo. 3. ed. São Paulo: brasiliense, 1994. p. 133.

${ }^{14}$ CORBIN, Alain. Dietro le Quinte. In: ARIÈS, Philippe; DUBY, George. La vita privata. L'Ottocento. Roma: Laterza, 2001. p. 369. 
O século XX agudiza esse processo de perda e - portanto - amplia a necessidade de um mergulho no passado, porque a insegurança do tempo presente traz um aumento na busca de raízes que denotem um pertencimento, uma durabilidade. Pensando essa discussão nos processos imigratórios na serra gaúcha, especificamente no fenômeno da imigração italiana, a partir dos anos 1960, percebe-se uma contínua perda das experiências comunitárias vividas pelos descendentes de imigrantes. Desde transformações internas que sofreram as comunidades, devido aos efeitos de um progresso econômico e industrial, até a saída de parte da população em busca de espaços de trabalho nas cidades, fruto de um processo acelerado de urbanização, observou-se uma desestruturação de referenciais comunitários, vinculados a codificadores das relações sócio-históricas.

A perda da tradição, como enfatizado anteriormente, produz uma constante busca de reviver o passado, de construir um significado ou produzir um percurso, ligando os diversos restos de um tempo não mais existente. Muitas vezes os projetos culturais e turísticos acabam construindo simulacros de uma quotidianidade acontecida. Enquanto se propõem a revelar o autêntico, a permitir que se veja as coisas como de fato o foram, esses programas ressignificam o real e constroem uma realidade passada estetizada, desprovida do efeito do tempo que frui:

É a ambivalência do real e da sua cópia, no momento em que as cópias são sempre mais realistas e o real sempre mais penetrado pelo simulacro e pela ficção. ${ }^{15}$

Essa representação do passado, que passa a ocupar o lugar do real acontecido, é a matéria-prima por excelência da nostalgia, porque o nostálgico busca mais os pensamentos passados que as coisas passadas. Não é a ruína por si que produz o interesse do homem moderno, mas a possibilidade de evasão que ela permite, o poder reconhecer - através do vestígio - a imagem do real acontecido que está cristalizada em sua mente:

O que agrada ao nostálgico não é a relíquia, mas seu próprio reconhecimento da mesma, não tanto o passado em si mesmo, mas as aspirações que se supõe que ele tenha; menos a recordação daquilo que ocorreu realmente, que o que em outro tempo se pensou que era possível. ${ }^{16}$

${ }^{15}$ AUGÉ, Marc; AUGÉ, Marc. Rovine e Maccerie. Il senso del tempo. Torino: Bollati Boringhieri, 2004. p. 57.

${ }^{16}$ LOWENTHAL, David. Op. cit. nota n. 07, p. 34. 
Nesse sentido, tanto o projeto relativo aos "Caminho de Pedra" quanto àquele que promove o passeio na "Maria Fumaça" trazem a magia de sonhar um tempo que não se viveu, mas que pertence a um período onde tudo era melhor. Efetivamente produz a idéia de um tempo que não flui mais, permanecendo imutável em um eterno presente. As experiências do hoje são a continuidade desta eternização do passado, fruto de um processo de recordação do que se pensou ser o real passado.

A estruturação dos "Caminhos de Pedra" - no interior do município de Bento Gonçalves - encaixa-se nessa busca contemporânea de trazer a vida o passado, como se o tempo não tivesse exercido sua misteriosa ação sobre a trajetória daqueles homens. Com clara intenção turística - o projeto foi idealizado e implementado pelo Hotel Dall'Onder, a partir de diversas parcerias - inclusive da região do Vêneto. O roteiro propõe - de acordo com fôlderes divulgativos - trazer à luz o vêneto rural do século XIX. Para esse intento, a rota - antiga ligação entre Bento Gonçalves e Farroupilha - sofreu um processo de restauração em diversas habitações que se encontravam em seu percurso. Procurava-se destacar o autêntico, mostrando como eram as edificações quando da chegada dos imigrantes e como esse Vêneto rural tinha permanecido intacto na região serrana.

A nostalgia de um tempo melhor que existiu no passado marca a sua positividade e segurança, pois se contrapõe a realidade do presente - sempre negativa - e a insegurança do futuro, o qual se apresenta etéreo. Essa realidade produz um mercado turístico que se propõe a vender emoções ao nostálgico, promovendo o reconhecimento deste lugar estranho que é o passado: "Se o passado é um país estranho, a nostalgia o tem feito 'o país estranho com o mercado turístico mais saneado que existe",. ${ }^{17}$

Nesse sentido, o "Projeto Cultural" - como é denominado pelo Hotel Dall'Onder - visa instituir-se enquanto um "museu vivo da imigração italiana". ${ }^{18}$ Entende construir uma presentificação do passado - ou melhor - o seu renascimento, os "Caminhos de Pedra" produzem um efeito de real e constituem-se em uma representação, em uma memória da imigração, engendrando em si uma dimensão criativa. Esse percurso efetivamente constrói realidade e apresenta-se como crível para os inúmeros turistas que cruzam a região, em grande maioria provenientes

17 Idem, p. 29.

18 http://www.dallonder.com.br/passeios/passeios.htm\# - consultado em 18 de julho de 2004 . 
do centro do país e, também, para muitos descendentes de imigrantes que retornam em busca de seu passado familiar. Ao jogar com a ruína, com o resto, o efeito da restauração cria uma ficção embasada em fragmentos de realidade, destrói e reconstrói para produzir o consumo.

Lembrando a discussão de Primo Levi, o passado é duplicado pelo Mimete e sua cópia toma o seu lugar, apresentando-se como se efetivamente fosse o real acontecido. Para aquele que transita por entre as relíquias, essas imagens do passado suscitam mnemonicamente experiências passadas - vividas ou recordada nas narrativas de parentes e amigos - funcionando como mnemagoghi, nesse caso, de uma leitura daquilo que um dia existiu.

De qualquer forma, antes de continuar, faz-se necessário identificar ao que especificamente se está fazendo referência quando se discute essa antiga rota entre Bento Gonçalves e Farroupilha. O chamado "Caminhos de Pedra", o qual buscava resgatar a história dos primeiros imigrantes italianos no Rio Grande do Sul, no intuito de "mostrar como era", compõem-se de construções - muitas em pedra - que remontam ao período inicial do fluxo imigratório na região serrana, entre 1880 e 1900. Destacam-se algumas habitações do roteiro, como a casa Bertarello, a ferraria dos Ferri, a casa das massas e a cantina Strapazzon.

A casa Bertarello é um sobrado em pedra, com balcão frontal - com cantina - o qual reproduz a arquitetura da região montanhosa do norte italiano. A ferraria dos Ferri constitui-se de um pavilhão de madeira, com um moinho acoplado, o qual mantém instrumentos de trabalho que identificam as funções de ferreiro, na virada dos séculos XIX e XX.

Seguindo a rota, ainda na comunidade de São Pedro, tem-se a casa das massas, um sobrado em madeira - sem balcão e com cantina - que disponibiliza a venda de biscoitos e massas, apresentando instrumentos de produção caseira da pasta. No piso da "cantina", tem-se uma pequena tecelagem, com produtos em lã e linha para venda. Por fim, a casa Strapazzon, uma habitação com um primeiro andar e um mezanino, toda em pedra, que é utilizada hoje como lugar de armazenamento de uma produção caseira de vinho e de derivados da uva, sendo lugar também de degustação.

Destaca-se que - particularmente nessas duas últimas casas mencionadas - faz parte da narrativa a vinculação com o passado. $\mathrm{Na}$ casa das massas entende-se essa ação forte da busca do autêntico, pois na fala do administrador e de outros membros da comunidade, a casa que existia antes do restauro foi refeita - aos moldes da original. Dessa forma, conta-se que a habitação originalmente possuía dois pisos além 
da cantina; porém, com o empobrecimento e diminuição da família, destruiu-se o piso superior, pois era oneroso mantê-lo. Para o projeto, refez-se o segundo piso, praticamente destruindo o primeiro, pois as madeiras, como no original, deveriam ser inteiras. Cumpriu-se a meta - o tempo não passou e a habitação renasceu mais bem estruturada que quando foi construída pela primeira vez. Como em um efeito mimetizador, a estrutura arquitetônica passada surge como um duplo no presente - igual como havia sido em sua primeira edificação: o tempo parou!

$\mathrm{Na}$ cantina, antigamente último ponto do roteiro, menciona-se sempre - como ponto valorativo da construção - o fato de cenas do filme "O Quatrilho" terem sido rodadas em seu interior, pois ela refletia esse momento histórico. Como parte da construção imagética, a fala do demonstrador significa a habitação, informando que ela foi a moradia dos "nonos" recém-chegados, permanecendo sempre com a família.

Como em um roteiro museológico, haja vista que a proposta da estrada é um "museu vivo da imigração", faz-se referência ao contexto, remarcando sempre o caráter de fidelidade às tradições italianas do vêneto rural do século XIX. Inclusive, são utilizados esses "restos" dialetais como forma de produzir uma sensação de viagem temporal, possibilitando esse renascimento do passado. Constrói-se, dessa forma, a marca da ruína que se apresenta como o real acontecido.

Essa positividade expressa nos "Caminhos de Pedra" soma-se a uma leitura positiva construída na região do Vêneto, com relação à presença de seus egressos nas diversas partes do globo. A rota é divulgada no informativo da associação Veneti nel mondo, no mesmo número em que se anuncia o novo assessor regional para os fluxos migratórios - Raffaele Zanon - em junho de 2000, o qual destaca essa importante atuação dos emigrantes Vênetos no mundo:

Se o Vêneto é uma região que apesar de tudo muito contribuiu ao fenômeno imigratório nacional no transcorrer dos últimos dois séculos, a Região do Vêneto tem agora o compromisso de transformar esse grande êxodo em recurso tanto para aqueles que permaneceram quanto para aqueles que souberam - em todas as partes do mundo - promover a valorização da própria terra de origem. ${ }^{19}$

${ }^{19}$ Veneti nel Mondo - periodico della Regione Veneto per i veneti all'estero - giugno 2000 - http://www2.regione.veneto.it/videoinf/periodic/precedenti/00/6/index.htm consultada em 18 de junho de 2004 . 
Nesse sentido, observa-se um interesse da própria região do Vêneto em efetivamente promover iniciativas que ressaltem a presença dessa cultura regional e seus elementos de positividade. Assim, reelaborar essa trajetória vitoriosa dessas populações imigradas - destacando esse fenômeno de venetização que se dará a partir da década de 1970 é contribuir com essa iniciativa de "manter alto o nome da terra de origem".

Como em La bella addormentata nel frigo, as preocupações com uma identificação regional são congeladas e descongeladas em momentos históricos específicos, de acordo com as necessidades do presente. A identificação com uma matriz identitária ítalo-gaúcha produz sentido em um momento em que se busca reviver o passado, pois a realidade da vida - no hoje - apresenta-se de maneira negativa.

Outro elemento que constrói uma imagem de não-mutação das culturas e de atemporalidade dos processos emigratórios, é sua percepção de um mesmo "indivíduo vêneto" em todo lugar do globo e de uma vinculação natural entre aqueles que partiram e aqueles que permaneceram:

Deixamos para trás os velhos esterótipos que enxergavam a administração pública relacionar-se com as nossas comunidades no exterior, como se fossem entidades separadas do Vêneto, necessitadas apenas de alguma presença saltuária que fosse solicitada pelos sentimentos de nostalgia e pelo sentido de pertencimento à pátria distante. Hoje nós consideramos $i$ veneti nel mondo, os emigrantes e os seus descendentes, como efetivamente nossos co-regionais. ${ }^{20}$

Analisando essa idéia de forma individual parece apresentar-se apenas uma percepção administrativa; porém, quando se analisa o contexto da publicação e as diferentes matérias que versam sobre uma determinada "veneticidade", percebe-se essa identificação da região em seus fragmentos espalhados nos mais diversos recantos do globo. De certa forma, o olhar da região representa uma faceta desse fenômeno de retorno às origens e se associa a discussão de uma positividade da cultura vêneta, criando uma imagem diferenciada no contexto da formação nacional italiana.

O artigo - publicado na Revista Veneti nel mondo - busca reforçar esse retorno ao passado que a proposta permite, essa possibilidade de ver as coisas como realmente foram. Os "Caminhos de Pedra" são o passado vivo, possibilitando ver efetivamente como viveram essas comunidades 
de imigrantes quando de sua chegada no Brasil - ele elimina o tempo que passou - a ruína compõe um itinerário reificador do passado:

Caminhos de Pedra prevê não edifícios mumificados, mas ativos como no período em que foram construídos, com as mesmas atividades e os mesmos produtos, tanto que se pode falar em um verdadeiro "museu vivo". Foram efetivamente "chamados novamente ao trabalho" velhos artesãos da comunidade, os quais retomaram as suas tradicionais atividades, formando aprendizes como no passado. ${ }^{21}$

A estratégia de produção do real utiliza-se dos mais diversos recursos da sensibilidade - conjugando diferentes suscitadores de memória para essa reevocação do passado. Trabalha-se não apenas com o sentido visual, mas com a audição, a olfação e o tato. A idéia de mesclar as casas reestruturadas com as profissões que se desenvolviam na zona colonial permite essa viagem temporal, a partir de uma sensação do tempo recobrado.

Essas experiências da arquitetura e do entorno do projeto são um exemplo de resgate de um tempo perdido, promovendo um entrecruzamento no presente desses eu descontínuos, dessas personalidades sucessivas que fenecem na passagem do tempo. Constrói-se uma sensação de retorno, assim como Proust relata, de certos momentos em que o passado voltava à luz, a partir de sentimentos que se pensava houvessem desaparecido, mas que ao aflorarem, davam sinal de sua não-extinção - contexto notabilizado por Benjamin com o dístico "memória involuntária". Logo, Proust entende que o eu não vive uma constante destruição total de sua existência, mas permanece enquanto remanescência do passado individual e coletivo:

Nossos antigos eu não se perdem, em corpo e alma, já que podem reviver em nossos sonhos e, às vezes, ainda em nosso estado de vigília. [...] Assim, pois, o tempo não morre completamente, como parecia, senão que permanece incorporado em nós mesmos. ${ }^{22}$

Outro percurso turístico que se propõe a um "resgate" da história da imigração italiana é a "Maria Fumaça". Esse passeio consiste em uma viagem de trem - em um trajeto que liga Bento Gonçalves a Carlos Barbosa, na região serrana do Rio Grande do Sul - buscando reviver as viagens dos imigrantes e descendentes - nessa região - nas primeiras décadas do século XX. Na própria estação de Bento Gonçalves - um dos pontos de partida do passeio - existe um serviço de fotografias antigas, $\mathrm{O}$

${ }^{21}$ Idem.

22 MAUROIS, André. Em busca de Marcel Proust. Bogotá: Editorial Norma, 1998. p. 217. 
que permite colocar roupas do início do século passado, recriando-com o envelhecimento das imagens - uma sensação de ressurreição do passado.

No trem, depois da partida, diferentes grupos artísticos transitam pelos vagões, apresentando pequenos números musicais ou de teatro. Um casal, vestido conforme o estereótipo do colono, encena uma discussão, expressando a percepção do senso comum sobre "o colono italiano" e a imagem construída acerca da relação entre marido e esposa, no meio colonial. As questões relativas à bebedeira, a religião e ao adultério divertem os passageiros, reproduzindo e elaborando uma imagem sobre as relações familiares na imigração. Em um segundo momento, um grupo de canto passa pelo vagão, cantando músicas dialetais que fazem parte da simbologia identitária da imigração italiana, mais uma vez permitindo a percepção de um passado que retorna. $\mathrm{Na}$ estação intermediária - na cidade de Garibaldi - novamente se investe na música como um mnemagoghi do real acontecido, pois ela permite um sentimento do passado que se descongela.

As Storie naturali de Primo Levi permitem um olhar sobre a necessidade de guardar, produzida pela sociedade contemporânea, marca de um tempo que sempre mais constrói a percepção de sua passagem. Assim, o tempo enquanto subjetividade vive um processo de aceleração, construindo uma sensação de perda das experiências passadas, as quais se tornam fugidias. Assim, o nostálgico, a partir de estratégias que permitem a conservação dessas vivências, busca fazêlas ressurgir mnemonicamente: produzindo suscitadores de memória, máquinas de mimetização, ou descongelando - em alguns momentos - uma representação do passado.

Os descendentes dos imigrantes italianos - no Rio Grande do Sul - experimentam nos projetos culturais de "resgate" do passado, uma forma de superar esse contexto de perda da tradição rural que sofre na zona colonial. Esse itinerário que se articula nas comunidades da serra gaúcha - como construtor de links entre o passado e o presente, produz um efeito sublimador da nostalgia do tempo que passou. O fenômeno de presentificação do passado, de estetização das "ruínas étnicas" em um percurso que busca desconstruir a ação do tempo, embora tenha uma faceta positivadora da identidade étnico-cultural italiana, também produz uma possibilidade de auto-percepção da comunidade, criando realidade, mas colando-se a fragmentos do real - o que pode ser entendido, também, no sucesso econômico do empreendimento. Assim, nostalgia, mnemagoghi turismo e mimete se fundem, construindo um passado, pacificando o presente e produzindo uma nova sustentabilidade econômica para a região. 